\title{
Chapter 4 \\ Integration from a Commognitive \\ Perspective: An Experience \\ with Mathematics and Music Students
}

\author{
M. Alicia Venegas-Thayer
}

\begin{abstract}
Since one of the keywords in the interdisciplinary discourse is integration, the aim of the study was to describe the actions of participants that could be considered as part of an integration process involving mathematical and musical discourses. Based on the commognitive perspective developed by Anna Sfard, which argues that communication is a collectively performed patterned activity, here integration is a way to develop a new type of communication. Music and mathematics students participated in an experience, where it was possible to observe how line graphics of random data were interpreted through actions from a musical discourse and how the students developed a new form of communication when talking about chords, which they called "baggies".
\end{abstract}

Keywords Commognition - Interdisciplinarity - Innovation • Higher education • Random variable

\subsection{Introduction}

During the 1950s, architect and composer Iannis Xenakis (1922-2001), developed a method for musical composition called 'Stochastic Music'. It is music constructed from the principles of indeterminism, where the laws of probability become a necessity in the process of composition (Xenakis, 1963/1992). His music works are characterized as sound clouds, where every sound particle contributes to the work as a whole (Abornés \& Milrud, 2011). His motivation was not the need to include mathematics in the process of musical creation, but rather to consider music and sound as media and thus allowing the materialisation of creations of the human thought (Xenakis, 1963/1992). Using mathematical notions of probability, algebra and group theory, Xenakis defines the transformations that each sound entity will have throughout the playing. This music-mathematical relationship is widely described in his book called 'Formalized Music' (Xenakis, 1963/1992).

M. A. Venegas-Thayer ( $₫)$

Pontificia Universidad Católica de Valparaíso, Valparaíso, Chile

e-mail: aliciavenegasth@gmail.com

(C) The Author(s) 2019

B. Doig et al. (eds.), Interdisciplinary Mathematics Education,

ICME-13 Monographs, https://doi.org/10.1007/978-3-030-11066-6_4 
The use of technology has led composers to create works that in other ways would not be possible, where mathematical and physical models together with these tools are now part of the musician's problematic (Cádiz, 2012; Ferreira, 2001). This change in practice and musical discourse opens the door to new forms of composition and musical production in general, where mathematicians and musicians can carry out a creation process interacting collaboratively. Examples of contemporary composers are James Tenney, developer of an algorithm for the composition called dissonant counterpoint, considering a statistical and probabilistic background (Polansky, Barnett, \& Winter, 2011). An other example is Michael Winter, whose processes of composition and studies in musical theory are characterised by the collaboration not only with other artists but also with mathematicians and scientists. This musician-mathematical relationship is also reflected in the analysis of works and musical performances in which advanced mathematical procedures have been used for scientific music research in music theory (Noll \& Peck, 2007).

In these new scenarios, musicians and mathematicians have been introduced to practices and discourses that are not necessarily their specialty. As Boix (2010) describes it, participants of interdisciplinary processes have to "integrate information, data, techniques, tools, perspectives, concepts, and/or theories from two or more disciplines to craft products, explain phenomena, or solve problems, in ways that would have been unlikely through single-disciplinary means" (p. 289). During the process, the participants engage in a collaborative dialogue, "including debates and conflict, which both transforms the understanding of individual participants and produces new knowledge, new solutions, and even new disciplines that would not be possible without such dialogue" (Derry \& Schunn, 2014, p. xiii). In other words, those who make these new productions possible are the musicians and mathematicians involved in the process, whether through cross-dialogue with other specialists or through personal processes of study and research.

Since one of the keywords in any interdisciplinary discourse is integration (Klein, 2010; Newell, 2001), the aim of the study reported here was to describe the actions of participants that could be considered as part of an integration process involving mathematical and musical discourses. The framework of this research is the Commognitive Theory (Sfard, 2008, 2012), adopting a communicational perspective about thinking. According to Sfard (2008), communication-and therefore, thinking - is possible because of the habit of reacting to certain actions with certain kinds of reactions, so here integration is defined as a way to develop a new type of communication. Music and mathematics students participated in an experience, where it was possible to observe how line graphics of random data were interpreted through actions from a musical discourse and how the students developed a new form of communication when talking about chords, which they called "baggies". 


\subsection{Commognition: Thinking as Communication}

Starting from the premise that humans are socially committed from the day they are born, Sfard (2008) points out that human development is based on communication. As she describes it, thanks to communication, human beings have been able to satisfy from the basic necessities that keep them alive, to the most advanced and complex cultural demands. Built on the Vygotskian socio-constructive perspective where the "historically established, collectively implemented activities are developmentally prior to all our uniquely human skills" (Sfard, 2008, p. xvii), the author concluded: if human thinking is one of these skills, the most obvious collective predecessor is interpersonal communication (Sfard, 2008). She proposes a new way of thinking about thinking, pointing out "thinking can be usefully defined as the activity of communicating with one self" (Sfard, 2012, p. 2). The author defines communication as,

a collectively performed patterned activity in which action A of an individual is followed by action $\mathrm{B}$ of another individual so that (1) A belongs to a certain well-defined repertoire of actions known as communicational, and (2) action B belongs to a repertoire of re-actions that fit A, that is, actions recurrently observed in conjunction with A. (Sfard, 2008, p. 296)

That is, "what makes communication possible is the fact that the community got into a habit of reacting to certain actions with certain types of re-actions" (p. 88). Then she makes clear that this action and reaction relation does not only depend on the A action, but other factors, like the historical moment where A and B are performed, that is the context, the previous actions, the identities of the participants, and so on. Thereby, cognitive processes and communicative processes are actually "different (intrapersonal and interpersonal) manifestations of the same phenomenon" (p. 296), and Sfard integrates these under the term commognition.

From this definition, Sfard (2008) deduces the existence of different types of communication or types of commognition, called discourses. Each discourse is characterised by: keywords, visual mediators - those visible objects used in any process of commognition and symbolic artefacts from specialised discourses like science or mathematics - distinctive routines or patterns of how to perform some tasks, and their endorsed narratives, those that the community has labelled as true (Sfard, 2008, 2012). There are no explicit boundaries between one discourse and another and there is even a mutual collaboration. Nevertheless, they may become sufficiently distinguishable from each other. The discourses are not stable entities, but on the contrary, they change over time. Changes in a discourse mean changes in the way of communicating, which directly influence human practices, and vice versa, changes in practice imply changes in discourse (Sfard, 2008, 2012).

According to these definitions, Sfard (2008) argues that mathematical thinking-or mathematics - is a discourse, with the following characteristic features: keywords (three, triangle, set or function, among others), visual mediators (numerals, algebraic symbols, and graphs), distinctive routines-patterned ways in which mathematical tasks have being performed-and generally endorsed narratives, that is theorems, definitions and computational rules (Sfard, 2008, 2012). In the same 
way, one can distinguish the discourse of algebra, of geometry, and of functions (Sfard, 2012). On the other hand, there are discourses about music and sounding phenomenon, with their own keywords (pitch, chords, musical scales or harmony), patterned ways in which musical task are performed, visual mediators (music stave, notes values) and it is also possible to talk about endorsed narratives accepted by a musical community, such as principles about harmony, just intonation or Pythagorean tuning.

Those "individuals capable of participating in a given discourse" (Sfard, 2008, p. 299) constitute the community of discourse. Sfard distinguishes between a person who belongs to this community, an insider, and a "person incapable of participating in the discourse" (p. 300), an outsider. The distinction and consideration of both perspectives can enrich the analysis of the discourse in question. According to Sfard, "what is senseless or inexplicable in the insider's eyes may become meaningful for an outsider, if only because from the outsider's perspective, the rules of the discourse in question do have alternatives" (p. 279).

As was mentioned above, integration is one of the keywords of any discourse about interdisciplinarity. So, this research has focused on characterising integration from the actions of individuals participating in an interdisciplinary process. To do so, an operational definition is required. Drawing from commognitive discourse, integration is defined as a process through which one or more individuals develops a new discourse by adapting and modifying keywords, mediators and/or procedures belonging to different discourses in a way that allows them to achieve a specific goal.

\subsection{The Interdisciplinary Collaboration Experiences}

If the discourse is a type of communication, this is characterised by a set of actions and reactions practised by the discourse community, so "development of discourse is, by definition, a product of collective human actions" (Sfard, 2012, p. 02). To describe those collective human actions associated to an integration process, an experience for university students of music and mathematics was organised, inspired by the methods of Stochastic Music composition developed by Iannis Xenakis. The problem proposed to the participants was as follows: compose a piece of music from the data obtained by repeatedly throwing a fair coin. It was raised in order to promote dialogue among the participants, so that they have to decide how to proceed and thus respond to the challenge. It was designed to be a two-hour session, beginning with a brief description of stochastic music, where they heard part of the piece "Metastasis" from Xenakis (1954/1965, track 3). Then, the problem was presented without giving further explanation, inviting participants to empower themselves through the problem by addressing it in their own way. Since it was planned for a session, it was expected that the participants would define a strategy for a musical composition, rather than compose a piece of music. 
There were no preconditions about music and mathematics knowledge stipulated to participate. Two mathematics students and three music students accepted an invitation to participate in a two-hour activity, independent from their curricular requirement and schedule. The five students belonged to the same university in Valparaíso, Chile. Two experiments were organized, five days apart. For the first one, the author of this report participated as a practitioner in mathematics, together with a music student, who specialised in musical composition. For the second, two music students and two mathematics students, currently enrolled in their third or fourth year of their careers, were involved.

One situation from each experience was selected for this chapter, where it was considered that the participants' actions were an integration process. In both cases, the participants interpreted a characteristic feature of one discourse in terms of the other. The first one shows how the musician described a line graph in terms of musical discourses, and the second shows the students using the keyword "baggie" when talking about chords.

\subsubsection{First Experimentation of Interdisciplinary Collaboration}

Before the session, the mathematician prepared a spreadsheet of a simulation of one thousand tosses of a fair coin with results coded in terms of 0 (head) and 1 (tail). She organized the spreadsheet in tables and graphs, where it was registered the results of each toss, the absolute and relative frequencies and the difference between the number of heads, and tails were included.

Trying to provoke some interest in the data, the mathematician shows to the musician the graph of the differences between the number of heads and tails (Fig. 4.1). The musician points out that the graph could be a little melody. While indicating to the highest vertex of the graph, he says that this could represent the climax of the melody. He explains that any melody, no matter how complex it may be, is a combination of moments of tension and release. To exemplify this, he improvises a solfeggio while assigning notes to the vertex of the previous graph, starting with the notes $\mathrm{C}, \mathrm{E}$, and $\mathrm{G}$. The highest notes, such as G, are the tension, after that, they go down and a release begins. The Fig. 4.1 represents what the musician described from the graph of the differences, but this is not an illustration built during the session.

During this conversation, he also suggests that the graph can also be inverted and says: "I think, this does not alter the mathematical relationship, because you are seeing it as in a mirror. It's like you have a mirror here and you're looking at it on the other way".

After almost an hour of conversation, the mathematician (MA) proposes to systematise the ideas they have been working on. The musician (MU) asks her to share the spreadsheet and the following dialog takes place:

MA: From this spreadsheet, what information do you prefer? 
MU: Graphs. Ideally, graphs, you know? Because... yes, I'm going to see the numbers... I'm going to do it! But, it is going to take me some time.

MA: No. it's OK.

MU: But this is visual. And especially because I can see the distances, you know? For example, the distance from here to here [pointing to the tosses number 8 and 12 from the Fig. 4.1]

MU: Where I see more variation between tension and release, I would assign a melodic value. The music is very graphic. If I show you sheet music, you will see that the tension parts are below or above, but they can be differentiated. That is a climax, is very clear (Fig. 4.1), little weird because it usually goes lower, but still good.

(...)

MU: For example, the graph below is also good... the one that you have below (Fig. 4.2)

MA: That one has more coin tosses.

MU: Leave it... ¡Look! This is very good too. It is a classic little movement. We should have to assign a time value.

MA: OK.

MU: And that time value, we could also assign it with another graph, you know?

The musician uses the expression "melodic value", when the graphic can be interpreted in terms of pitch, meaning that the graph can represent a sequence of pitches, like in Fig. 4.1. The "time value" expression, he related to the duration of each note, but this kind of value was not exemplified on any graph in particular and it was just mentioned.

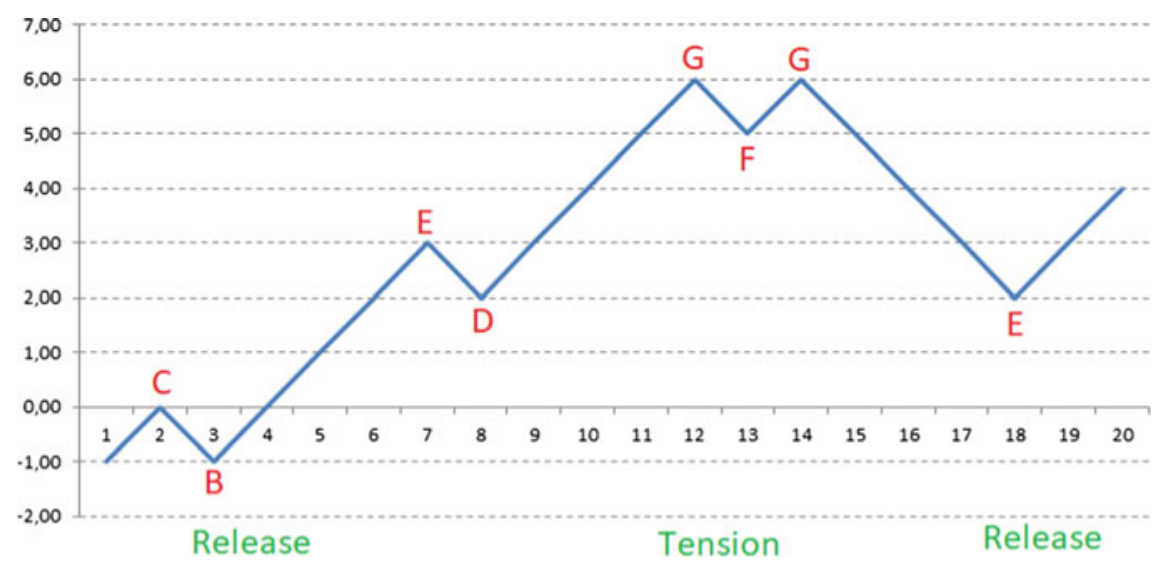

Fig. 4.1 Representation of the musician's example about tension and release 
The participants decided to have a second session, which was not planned at the beginning of the experience. In that session, they focused on exploring and selecting a line graph that they found melodically interesting. Once they selected the graph, they create a spreadsheet to convert these random geometric shapes into pitches (A, A\# B, C, C\#, D...) and notes values (semibreve, minim, crotchet and so on). Finally, the participants transcribe these results to a staff using Version 2011.r2 of Finale (2011) and program them in Csound (Version 5.0; Vercoe \& Fiftch, 2005), an audio programming language.

Figure 4.3 shows the line graph selected by the participants and the musical score obtained from that graph. To corroborate his idea about music being "very graphic", the musician makes a comparison between the curve made by following the heads of the musical notes on the sheet and the form of the line graph, showing that both have very similar shapes.

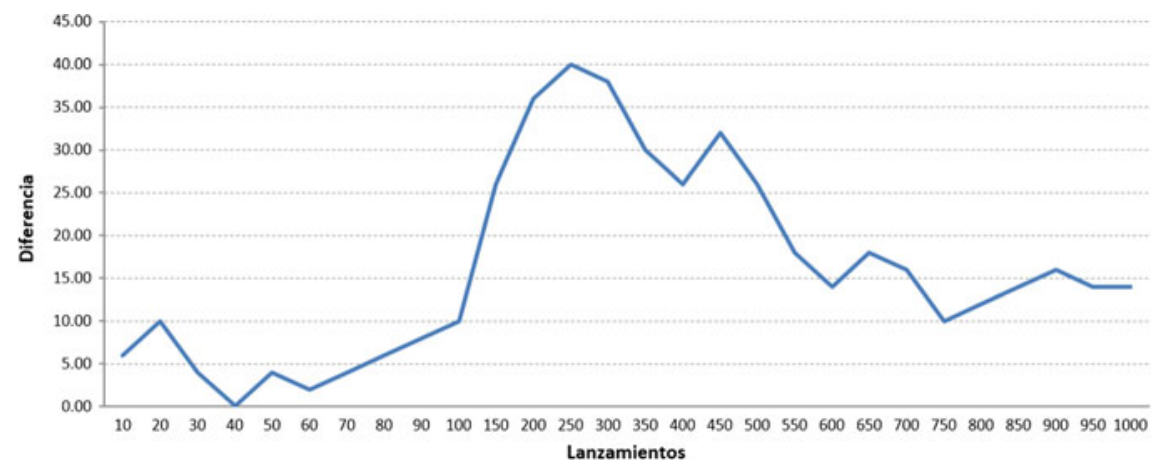

Fig. 4.2 The difference between the number of heads and tails over 1000 results

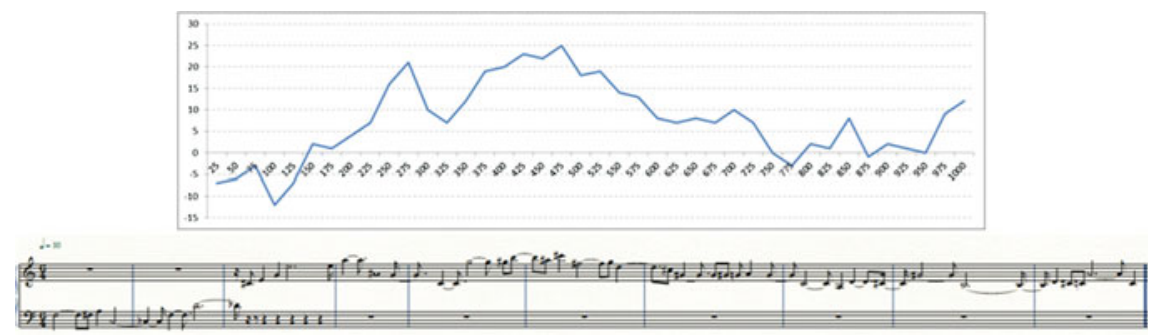

Fig. 4.3 The students' selected line graph and its interpretation as a melodic piece on sheet music 


\subsubsection{Second Experimentation of Interdisciplinary Collaboration}

Two music students, MU01 and MU02, and two mathematics students, MA01 and MA02, participated in the second experimentation. After the participants hear the Xenakis music piece, MU01 makes a description of the composition process, stating that Xenakis must have made a list with all the options for each aspect of musictimbre, pitch, intensity, dynamics and duration. This utterance makes sense to MA01, because this kind of action is usually part of any activity in probabilities, that is, to recognise all the possibility when studying a random experiment. After $10 \mathrm{~min}$ of conversation, where the musicians showed the mathematicians a variety of factors to consider when composing, the students decided to make a composition for three kind of instruments: melodic, rhythmic and harmonic. To write the score and to simulate the instruments during the process, they used a scorewriter program called Sibelius (2011).

During the session, the student who led the group is the musician MU01. At the beginning of the composition process, he makes a list of the note values, its corresponding rests (intervals of silence) and a list with the 12 notes of the tempered scale (Fig. 4.4). The students will use these lists during the whole activity, which will allow them to identify the options available to define rhythms and melodies for the composition. They also agree that for each instrument, they are going to calculate only 10 notes or chords, just to check whether the procedure is right or not.

The following description focus only on the piano, particularly the creation of chords from random data. Since the piano is the harmonic instrument of the composition, they have to define chords instead of sequences of notes, that is, sets of two or more notes played simultaneously. At the beginning of this task, the participants present a series of ideas to do this. For example, MU02 suggests considering threenote chords; MU01 proposes focusing on the fingers of the hand and their position in the piano instead of the musical notes; MA02, to do a combination of 4 notes from 12 to determine all the four-note chords possibilities. Then, MU01 explains the structure of the piano as sequences of 12 notes repeated in different octaves; MA01

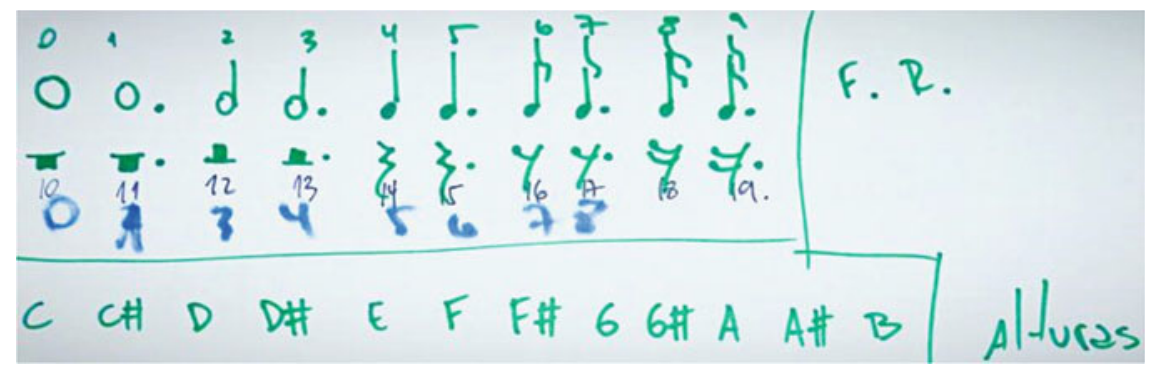

Fig. 4.4 List made by MU01 with the note values, rest values and pitches used for the composition process 
suggests to determinate the notes for each hand, because a hand can reach the twelve notes of an octave. MU01 proposes to use four-note chords, while he is drawing four vertical marks attached to a kind of ellipse (first ellipse on Fig. 4.5) and MU02, to consider all those notes with the same duration.

During this conversation, MA01 asks about how many kinds of chords exist, and the musicians explain there are no restrictions on the pitches of a chord and the only restriction is the number of notes, because this cannot be more than the number of fingers from both hands. Then the interchange continues mainly between MA02 and MU01 about the number of notes that a chord could have. MA01 intervenes as shown in the following dialogue:

MU01: We have the possibility that... it will be... look it is going to be ten chords. MA01: We must do... we must do...

MU01: Look, we must do ten chords.

MA01: We must do ten baggies and each one could have from one to ten.

MU01: From one to ten [simultaneously with MA01]

MU01: Yes.

MA01: And the duration is per baggie.

MU01: Yes, per baggie, per baggie.

MA02: Yes, and also the notes of each baggie.

MA01: We could have baggies of 5 or baggies of 10. Right? Anything [smile]

MA02: Yes. And that tells you how many fingers you are going to use, that means, how many pitches. And then, with those pitches, we see which of these [note values] is going to be [while she is pointing to the list of Fig. 4.4]

MU01: Yes, which note value is it going to have [the baggie]

MU02: Yes. And that is the reason why we have 10 notes, because we have 10 fingers.

The other participants immediately adopt the term "baggie" and they use it during the rest of the experience. On the same page where the musician draws the ellipse with the four marks (Fig. 4.5), MA01 adds seven more ellipses to represent the baggies

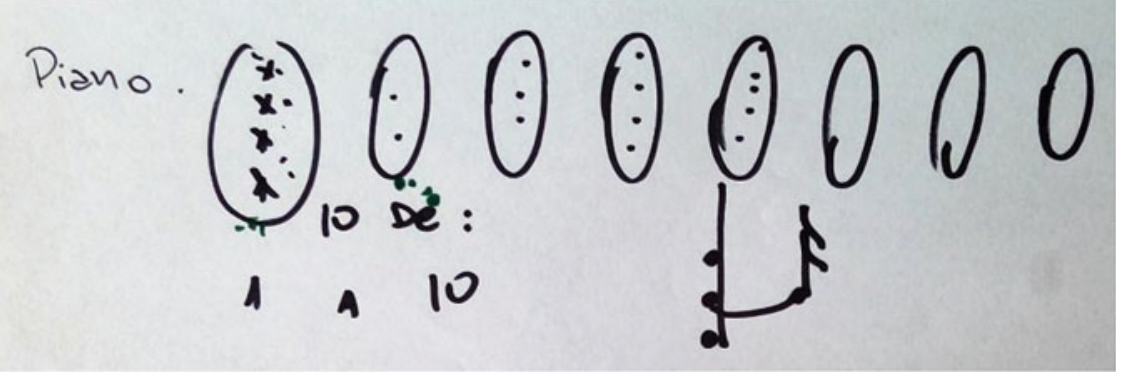

Fig. 4.5 Ellipses drawn by MU01 and MA01, representing baggies with different numbers of notes between 1 and 10 
they are going to do for the composition. Inside each one, MA01 marks different numbers of points, exemplifying numbers of randomly chosen notes.

When the structure of the object referred to as a baggie was clear, MA01 perceives that the pitches will always be in the same octave. He expresses his perception by pretending to play a piano with both hands together in front of him and he warns it is going to be 10 notes from 12, reopening the debate about the number of notes per baggie. Thus, they modify it into two baggies of five notes-one baggie for each hand-so both hands could play on different octaves. This organization makes more sense to MA01, who simulates playing a piano by moving both hands in opposite directions.

Finally, the information of a baggie consists of five random variables: the number of digits (0-5), note values (0-9), pitch for each finger (0-11), and octave per baggie (1-5). The mathematics students make a visual representation of a baggie, which indicates all the information needed to define the piano chords played with one hand (Fig. 4.6).

Given these options, the mathematics students decide that the probability model could no longer rely on coin tosses but dice. For each random variable of the baggie (K, F, A and O), they would need a different dice, where its number of faces depends on the number of options, ensuring equal probability of success for each value. For example, the $\mathrm{F}$ random variable of note values requires a 10 -sided dice with results between 0 and 9 . They use a spreadsheet to simulate them. The mathematicians also note that the lists of baggies for the hands are independent of each other, so it may happen that the duration of one list could be longer than the other one. This last statement is clear for the musicians, who do not see a problem if the pianist only plays with one hand at the end.

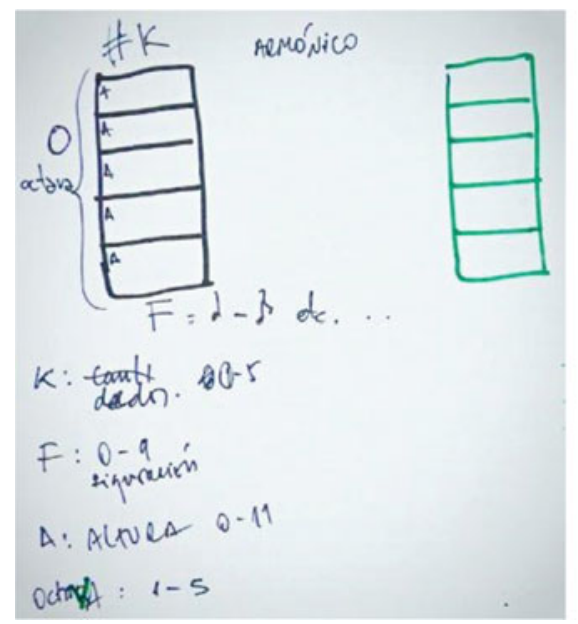

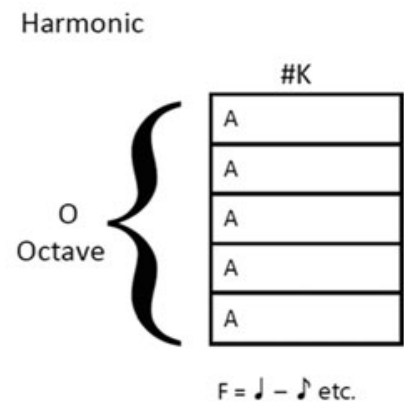

K: Number of fingers. 0 to 5

F: Note values. 0 to 9

A: Pitches. 0 to 11

O: Octave. 1 to 5

Fig. 4.6 Students visual representation of information of a baggie 


\subsection{Results}

In commognitive research, the discourse is the primary unit of analysis (Sfard, 2008). The situations described above could be associated with a particular discourse, whether mathematical or musical, so a study from the outsider's and an insider's perspective was conducted. The first case was approached considering the line graph as a visual mediator from a mathematical discourse. Therefore, the mathematician gives the perspective of the insider, while the outsider corresponds to the musician. However, it is important to note that when the musician performs his musical interpretation of the graphics, the mathematician becomes an outsider, trying to follow the musician's explanation. As for the case of chords and baggies, the insider's perspective corresponds to the musician, considering chords as a keyword of a musical discourse.

Each experiment was analysed from videos and audio recordings, paying attention not only to verbal language but also to gesticulation, written records and resources. To gain evidence of the insider and outsider perspectives, interviews of participants based on recordings of critical moments were used. It should be noted that after reviewing the videos, setting up a meeting with each participant took more than five months, so having the video during the interview was important to stimulate recalls.

\subsubsection{About Line Graphs and Music Reading}

During the first experiment, the line graphs became a meeting point between the participants and established the tone in the composition process. The musician interpreted this visual mediator, which is characteristic of a mathematical discourse, considering a discourse that was more familiar to him. He associated this mathematical mediator with one of his practices: the reading of sheet music. On a sheet music, every note is displayed from its duration and pitch. The note value represent the duration, and its location on the staff, the pitch. Two dimensions, ordinal and intervallic, determine the pitch. Ordinal indicates that the notes are ordered from the top to the bottom, from high to low; intervallic, the distance between the notes reflects the difference of tones (Galera \& Tejada, 2010; Schön \& Mireille, 2002).

The musician's utterances about the graphs were only associated with the shape of the polygonal curve, he did not worry about the information provided by the axes. This was more evident when the musician mentioned that the graph could be inverted without affecting the mathematical relation. This practice of inversion could have been accepted, considering that the participants defined their process according to a melodically interesting graph, and for that, it was enough to observe its form, but could also depend on how faithful to the graph information the participants would like to be. Although this idea was not used, a consideration emerged from it: the interpretation of a discourse in terms of another brings with it features of the other discourse that might not correspond or even be contradictory to the initial one, "like 
Trojan horses that enter discourses with hidden armies of unhelpful entailments" (Sfard, 2008, p. 35).

Another important factor in this integration process was the technology. To use technology for teaching and learning statistics and probability allows focusing an activity on the conceptual analysis rather than numerical calculation. Different methods of analysis and interpretation of large data sets are endorsed, such as simulations of random experiments, generations of different representations and automation of calculations and procedures (Chance, Ben-Zvi, Garfield, \& Medina, 2007; Friel, 2007). The management of the spreadsheet by both participants characterised this experience. Having this tool made it possible to search the melodically interesting graphic, but also to simulate the experiment looking for other results beyond the heads and tails result.

\subsubsection{About Baggies and Gestures}

During the session, chords were approached through explanations and gestures associated with playing chords on a piano. These gesticulations were simulations of playing a piano using both hands and they were performed by music and mathematics students. Even when the students talked about a pianist playing the chords, the gesticulations were as if they were "the person performing the act, rather than taking the viewpoint of an observer of the event" (McNeill, 1992, p. 119). These gestures were as important as the talking explanations. For instance, the changes in the baggies structure from one to two baggies, one for each hand, emerged from this kind of gesture. MA01 declared during the interview, "This is logical. Although one does not know much about playing the piano, one knows that the hands are normally separate. So, it called my attention that we did it from zero to ten", explaining how he made the decision to use two baggies instead of one.

While the participants were arguing about the number of notes each chord would have in their composition, MA01 introduced the term baggie. In the interview, he explained that this idea came out when he associated the chord with the mathematics notion of set. Based on his interpretation, a chord was a set of notes and the clearest way to explain this to the musicians was using the term baggie. Therefore, the student used it when he associated the musical discourse on chords with a mathematical discourse that he knew, set theory, where "baggie" only facilitated communication with the musicians.

The baggie metaphor helped the students simplify the notion of chord, stripping it of any other characteristic as a musical object, which was not relevant at that moment, focusing their attention on what was under discussion: the notes of a piano chord. Even some of the ideas from the beginning of the discussion were mentioned again, but now the conversation seemed to be more fluent, and all ideas converged to a same goal. These students' conversation was interpreted as the emerging of a type of communication. It was possible to recognize new actions and reactions around some keywords, "baggie" being the most important. So, the discourse about 
baggies is about an organisation of all the random variables needed to define a random chord: the number of notes (or fingers), pitches, duration and octave. With all this information, it was possible to write chords on a staff.

In addition, the students developed a visual representation of a baggie (Fig. 4.6), showing all the random variables and their options. This type of communication made all the participants insiders of this new discourse. However, this role was not permanent throughout the activity. Participants returned to their roles of insiders and outsiders on several occasions. For example, when it was necessary to transcribe the information of the baggies into chords on a staff, only the musicians performed this task while the mathematicians were responsible for obtaining the random data for 10 baggies.

\subsection{Discussion}

This study delves into the actions of students while participating in an experience of interdisciplinary collaboration between music and mathematics at the university level. The actions associated with an integration process correspond to those where outsider subjects made an effort to make sense of the dialogue in terms of a discourse that was more familiar to them. For the two experiences described here, this interpretation occurred when the outsiders recognised in a visual mediator or in a keyword something that reminded them of one of their practices or discourses. However, the integration process could only continue when the insiders accept this interpretation. From that moment, the roles of insider and outsider became less evident in the conversation, and at some moments, all were insiders of this new type of communication that emerged from the same participants.

The distinction between the insider and outsider perspectives seems more evident when it comes to individuals belonging to different areas of knowledge, as it was in these cases, with music and mathematics students. However, at the school level, this distinction is not so obvious. Then, the question is, what happens when individuals whose specialisation is not given by any professional training carry out the challenge of integrating discourses?

The integration term is a contribution to the Commognitive Theory. The aim of incorporating this keyword to the theory is to analyse interdisciplinary activities in mathematics education, from the perspective of the development of new discourses. This is a first approach and new research is required to advance its development, considering these and other areas of specialisation. As the definition of integration indicates, this process is associated with a specific goal, that is, the new discourse arises from a particular need and emerges to respond to it. Therefore, the participants can develop and expand its field of action, according to their interest and objectives. This is something that was not addressed in these experiences, but it would be worth analysing in future.

At large, including the commognitive perspective to the inquiry of students' interpersonal communication broadened the viewpoint of what interdisciplinary research 
means, towards the development of new knowledge. In this sense, the design and analysis of interdisciplinary activities could be associated with collaborative innovation and creation. Universities, as multidisciplinary institutions, are ideal places to perform this kind of research or practices, carrying out activities that include students from different specialisations with the aim of putting their knowledge - or discourses, in commognitive terms - into perspective, through actions that implicate practice and integration of discourses.

Acknowledgements My thanks to Professor Dr. Jorge Soto-Andrade and the students who participated in these experiences. Also to the National Doctoral Scholarship 2015 from the Training Program for Advanced Human Capital. CONICYT, Government of Chile (Folio: 21151503) and the Basal Fund PIA-CONICYT for Centres of Excellence, Project BF0003.

\section{References}

Arbonés, J., \& Milrud, P. (2011). La armonía es numérica: Música y matemáticas [Harmony is numerical: Music and mathematics]. Villatuerta, Spain: RBA Coleccionables.

Boix, V. M. (2010). Learning to synthesize: The development of interdisciplinary understanding. In J. T. Klein \& R. C. Frodeman (Eds.), The Oxford handbook of interdisciplinarity. Oxford: Oxford University Press.

Cádiz, R. (2012). La creación musical en la era postdigital [Musical creation in the post-digital era]. AISTHESIS, 52, 449-475.

Chance, B., Ben-Zvi, D., Garfield, J., \& Medina, E. (2007). The role of technology in improving student learning of statistics. Technology Innovations in Statistics Education, 1(1), 1-26.

Derry, S., \& Schunn, C. (2014). Interdisciplinarity: A beautiful but dangerous beast. In S. Derry, C. Schunn \& M. Gernsbacher (Eds.), Interdisciplinary collaboration: An emerging cognitive science (pp. xiii-xx). New York: Psychology Press.

Ferreira, G. M. (2001). When art, science and technology meet: The strength, the dilemma or the curse of electroacoustic music? In Proceedings of the International Conference: Music Without Walls? Music Without Instruments? Montfort University.

Finale [Computer software]. (2011). Eden Prairie, MN: MakeMusic.

Friel, S. (2007). The research frontier: Where technology interacts with the teaching and learning of data analysis and statistics. In G. W. Blume \& M. K. Heid (Eds.), Research on technology and the teaching and learning of mathematics: Cases and Perspectives (Vol. 2, pp. 279-331). Greenwich, CT: Information Age Publishing Inc.

Galera, M., \& Tejada, J. (2010). Editores de partitura y procesos implicados en la lectura musical [Score editor programs and processes involved in music reading]. Revista Electrónica de LEEME [Lista Europea Electrónica de Música en la Educación], 25, 65-75.

Klein, J. T. (2010). A taxonomy of interdisciplinarity. In R. Frodeman, J. T. Klein, \& C. Mitcham (Eds.), The Oxford handbook of interdisciplinarity (pp. 15-30). Oxford: Oxford University Press.

McNeill, D. (1992). Hand and mind: What gestures reveal about thought. Chicago: University of Chicago Press.

Newell, W. H. (2001). A theory of interdisciplinary studies. Issues in Integrative Studies, 19, 1-25.

Noll, T., \& Peck, R. (2007). Welcome. Journal of Mathematics and Music, 1(1), 1-6.

Polansky, L., Barnett, A., \& Winter, M. (2011). A few more words about James Tenney: Dissonant counterpoint and statistical feedback. Journal of Mathematics and Music, 5(2), 63-82.

Schön, D., \& Mireille, B. (2002). Processing pitch and duration in music reading: A RT-ERP study. Neuropsychologia, 40, 868-878. 
Sfard, A. (2008). Thinking as communicating: Human development, the growth of discourses, and mathematizing. New York: Cambridge University Press.

Sfard, A. (2012). Introduction: Developing mathematical discourse-Some insights from communicational research. International Journal of Educational Research, 51, 1-9.

Sibelius [Computer software]. (2011). Burlington, MA: Avid Technology.

Vercoe, B., \& Fiftch, J. (2005). Csound [Computer software]. Cambridge, MA: Media Lab, M.I.T.

Xenakis, I. (1954). Metastasis [Recorded by Jean-Etienne Marie]. On Xenakis: Metastasis/pithoprakta/eonta [CD]. France: Studios de l'O.R.T.F. (1965).

Xenakis, I. (1963/1992). Formalized music: Thought and mathematics in composition (Sharon Kanach, compilation and edition). Stuyvesant, NY: Pendragon Press.

Open Access This chapter is licensed under the terms of the Creative Commons Attribution 4.0 International License (http://creativecommons.org/licenses/by/4.0/), which permits use, sharing, adaptation, distribution and reproduction in any medium or format, as long as you give appropriate credit to the original author(s) and the source, provide a link to the Creative Commons licence and indicate if changes were made.

The images or other third party material in this chapter are included in the chapter's Creative Commons licence, unless indicated otherwise in a credit line to the material. If material is not included in the chapter's Creative Commons licence and your intended use is not permitted by statutory regulation or exceeds the permitted use, you will need to obtain permission directly from the copyright holder. 